\title{
Atmospheric extinction in solar tower plants: absorption and broadband correction for MOR measurements
}

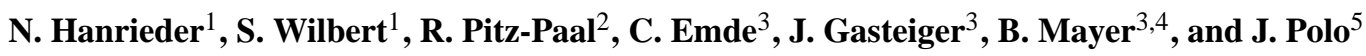 \\ ${ }^{1}$ German Aerospace Center (DLR), Institute of Solar Research, Plataforma Solar de Almería, Ctra. de Senés s/n km 4, \\ Apartado 39, 04200 Tabernas, Spain \\ ${ }^{2}$ German Aerospace Center (DLR), Institute of Solar Research, Linder Höhe, 51147 Cologne, Germany \\ ${ }^{3}$ Meteorological Institute Munich (MIM), Ludwig Maximilian University Munich, Theresienstr. 37, \\ 80333 Munich, Germany \\ ${ }^{4}$ German Aerospace Center (DLR), Institute for Atmospheric Physics, Münchner Str. 20, 82234 Weßling, Germany \\ ${ }^{5}$ Centro de Investigaciones Energéticas, Medioambientales y Tecnológicas (CIEMAT), Energy Department, \\ Renewable Energy Division, Avda. Complutense 40, 28040 Madrid, Spain
}

Correspondence to: N. Hanrieder (natalie.hanrieder@dlr.de)

Received: 22 January 2015 - Published in Atmos. Meas. Tech. Discuss.: 7 May 2015

Revised: 30 July 2015 - Accepted: 4 August 2015 - Published: 25 August 2015

\begin{abstract}
Losses of reflected Direct Normal Irradiance due to atmospheric extinction in concentrated solar tower plants can vary significantly with site and time. The losses of the direct normal irradiance between the heliostat field and receiver in a solar tower plant are mainly caused by atmospheric scattering and absorption by aerosol and water vapor concentration in the atmospheric boundary layer. Due to a high aerosol particle number, radiation losses can be significantly larger in desert environments compared to the standard atmospheric conditions which are usually considered in raytracing or plant optimization tools. Information about on-site atmospheric extinction is only rarely available. To measure these radiation losses, two different commercially available instruments were tested, and more than 19 months of measurements were collected and compared at the Plataforma Solar de Almería. Both instruments are primarily used to determine the meteorological optical range (MOR). The Vaisala FS11 scatterometer is based on a monochromatic near-infrared light source emission and measures the strength of scattering processes in a small air volume mainly caused by aerosol particles. The Optec LPV4 long-path visibility transmissometer determines the monochromatic attenuation between a light-emitting diode (LED) light source at $532 \mathrm{~nm}$ and a receiver and therefore also accounts for absorption processes. As the broadband solar attenuation is of interest for solar resource assessment for concentrated solar power
\end{abstract}

(CSP), a correction procedure for these two instruments is developed and tested. This procedure includes a spectral correction of both instruments from monochromatic to broadband attenuation. That means the attenuation is corrected for the time-dependent solar spectrum which is reflected by the collector. Further, an absorption correction for the Vaisala FS11 scatterometer is implemented. To optimize the absorption and broadband correction $(\mathrm{ABC})$ procedure, additional measurement input of a nearby sun photometer is used to enhance on-site atmospheric assumptions for description of the atmosphere in the algorithm. Comparing both uncorrected and spectral- and absorption-corrected extinction data from 1-year measurements at the Plataforma Solar de Almería, the mean difference between the scatterometer and the transmissometer is reduced from 4.4 to $0.57 \%$. Applying the ABC procedure without the usage of additional input data from a sun photometer still reduces the difference between both sensors to about $0.8 \%$. Applying an expert guess assuming a standard aerosol profile for continental regions instead of additional sun photometer input results in a mean difference of $0.8 \%$. Additionally, a simulation approach which just uses sun photometer and common meteorological data to determine the on-site atmospheric extinction at surface is presented and corrected FS11 and LPV4 measurements are validated with the simulation results. For $T_{1 \mathrm{~km}}$ equal to 0.9 and a 10 min time resolution, an uncertainty analysis showed 
that an absolute uncertainty of about 0.038 is expected for the FS11 and about 0.057 for the LPV4. Combining both uncertainties results in an overall absolute uncertainty of 0.068 which justifies quite well the mean RMSE between both corrected data sets. For yearly averages several error influences average out and absolute uncertainties of 0.020 and 0.054 can be expected for the FS11 and the LPV4, respectively. Therefore, applying this new correction method, both instruments can now be utilized to sufficiently accurately determine the solar broadband extinction in tower plants.

\section{Introduction}

One promising point-focusing solar-thermal technology is the solar tower plant technology. In contrary to linearfocusing systems, e.g. parabolic trough plants, a concentrator (in the case of tower plants called heliostat) is focusing the reflected solar irradiance onto a receiver on the top of a tower. A heliostat field consisting of many heliostats can therefore achieve high temperatures at the surface of the receiver due to the high resulting concentration factor. The direct normal irradiance (DNI), which is the important parameter for concentrated solar power (CSP) plants, is one part of the incoming solar radiation reaching the Earth's surface. It is known that the "sun belt" region is displaying high potential for CSP plant technologies due to the high DNI resources available. Large parts of this area are in semi-arid or arid conditions, like the largest desert of the world, the African Sahara. It is the primary source for mineral dust aerosol particles (Washington et al., 2003) and next to sea salt particles, mineral dust has a considerable contribution to atmospheric aerosol (D'Almeida and Schütz, 1983). Atmospheric aerosol extinction can lower the DNI reaching the surface by up to $30 \%$ (Gueymard, 2003). Especially in the lowest hundreds of meters of the Earth's atmosphere higher loads of aerosol particles like mineral dust or e.g. sea salt can be expected. This might be a crucial factor for solar tower plants. The solar radiation which is reflected by the heliostats to the receiver at the top of the tower has to travel a second time through the lowest atmospheric layers and this distance might be up to a few kilometers (depending on the solar field size). Therefore, the extinction has to be accounted for in solar resource assessment as well as plant optimization.

State of the art in tower plant models (which are both used for plant yield assessment and plant optimization) is that atmospheric extinction is modeled for standard atmospheric conditions. Some tools provide a choice of different attenuation conditions (Schwarzbözl et al., 2009; Belhomme et al., 2009; Buck, 2011; Kistler, 1986). For example in the DELSOL software by Kistler (1986) the default clear day with low aerosol and humidity load results in $10 \%$ DNI attenuation for a slant range (distance between heliostat and receiver) of $1 \mathrm{~km}$ (further denoted with $T_{1 \mathrm{~km}}$ ) and $25 \%$ on a hazy day. Even if some tools recently allow user-defined extinction input to provide eventually more accurate power output calculation, usually missing information about on-site extinction conditions is the main problem and the challenge plant operators are facing.

Ballestrín and Marzo (2012) describe spectral transmittance simulations performed with MODTRAN and found significant discrepancies between the performed simulations and the DELSOL and MIRVAL models. However, Sengupta and Wagner (2012) point out that the differences of the performed MODTRAN simulations by Ballestrín and Marzo (2012) mainly arise from the different elevations at which the simulations were made. The MODTRAN simulations have been conducted for sea level while the DELSOL and MIRVAL models were derived using data sets from a location at an elevation of about $600-700 \mathrm{~m}$ a.s.l. (Barstow, California). The MIRVAL code also allows to scale the atmospheric attenuation model with a factor called ABSORB according to the local atmospheric conditions. Ballestrín and Marzo (2012) assumed this factor to be equal to 1 as recommended for slant ranges up to $1 \mathrm{~km}$, receiver heights $100-300 \mathrm{~m}$ and an approximate altitude of $600 \mathrm{~m}$ a.s.l., see Leary and Hankins (1979). The conclusion of Ballestrín and Marzo (2012) that the basic DELSOL and MIRVAL codes are only valid for specific atmospheric conditions is therefore correct, but the MODTRAN simulations presented have not been performed for the according conditions. Additionally, as a reaction to this paper, the comment of Gueymard (2012) discusses the inaccurate broadband integration for transmittance which is performed in the publication.

There are several models developed to determine DNI attenuation and atmospheric extinction in the lowest layer of the atmosphere. The model of Sengupta and Wagner (2012) is based on on-site DNI ground measurements to estimate the AOD (aerosol optical depth) in the lowest atmospheric layers. Attenuation between a heliostat and a receiver is estimated only from these measurements. This approach is already implemented in the simulation tool named SoFiA (Solar Field Assessment for Central Receiver Systems) presented by Gertig et al. (2013). Tahboub et al. (2012) presented the "Swaihan Experiment" consisting of pyrheliometers in different distances to a heliostat and also the "Jebel Hafeet experiment" in the UAE (United Arab Emirates) which utilizes pyrheliometers located at different altitudes at the Jebel Hafeet mountain. The Pitman and Vant-Hull transmittance model (Pitman and Vant-Hull, 1982) was developed on the basis of a data set by Vittitoe and Biggs (1978). The software tool for layout and optimization of heliostat fields HFLCAL (Schwarzbözl et al., 2009) also provides in addition to the different attenuation levels the utilization of the Pitman and Vant-Hull model. It determines the atmospheric extinction in solar tower plants including 12 different specific atmospheric conditions, using standard atmospheres and assuming exponential decrease of air and aerosol density with height. For these reasons the model might not be rep- 
resentative for other atmospheric situations (e.g. low level haze). Nevertheless, additional input of meteorological optical range (MOR) and water vapor measurements in the Pitman and Vant-Hull model might improve the performance of ray-tracing tools significantly (Hanrieder et al., 2012).

Due to the limited knowledge about suitable sensors to measure the atmospheric extinction, Hanrieder et al. (2012) investigated different commercially available instruments and proposed one scatterometer from Vaisala (FS11) and one long-path visibility transmissometer from Optec (LPV4). To measure the MOR and therefore indirectly the transmittance (see Sect. 2.1), the scatterometer and the transmissometer have been chosen to perform continuous measurement at the Plataforma Solar de Almería (PSA) for more than 19 months. A data set of one complete year (May 2013 to May 2014) is intercompared and analyzed. Both instruments are measuring the MOR at one wavelength and are suitable for usage for onsite ground measurements. In both instruments the MOR is derived from extinction or scattering of monochromatic light. As the current reflected solar spectral transmittance (broadband transmittance) is the relevant parameter for CSP and the solar spectrum shows a considerable diurnal cycle and is also dependent on current aerosol conditions, a narrowbandto-broadband conversion has to be applied on the raw measurements of both sensors (Sect. 2.3.4). The instruments are further not equally considering the absorption (e.g. by water vapor) and scatter effects (Sect. 2.3.3). This has to be kept in mind if e.g. MOR measurements are feed into the Pitman and Vant-Hull model, and therefore it also has to be corrected to receive a satisfying corrected measurement result. After applying the here-presented correction procedure, both sensor measurements provide valuable input to CSP tools to significantly improve solar resource assessment.

\section{Methodology}

\subsection{Measurements}

Atmospheric extinction is caused by absorption and scattering. Aerosol particles and water vapor have an important influence on atmospheric extinction. A beam of incident light is partly attenuated while traveling through an atmospheric layer and parts are transmitted. The Beer-Lambert-Bouguer law describes the monochromatic transmittance introducing the spectral extinction coefficient $\beta_{\text {ext }, \lambda}$ :

$T(\lambda, x)=\frac{\operatorname{DNI}(\lambda, x)}{\operatorname{DNI}(\lambda, 0)}=e^{-\beta_{\mathrm{ext}, \lambda} x}$,

where DNI $(\lambda, 0)$ is the incoming spectral DNI at wavelength $\lambda$ and DNI $(\lambda, x)$ the spectral DNI after transmittance through a medium after a distance of $x$.

Atmospheric extinction is lowering the "visibility" which is often reported for traffic or aviation purposes. An exact knowledge about visibility is of importance for safety reasons. There are several definitions to describe the visibility in a distinct atmospheric condition (Gueymard, 2001). Usually visibility is referred to the definition by a human observer and therefore only a rough estimate. Another option to define the visibility is the MOR. The MOR is defined as the length of the path in the atmosphere which is required to reduce the luminous flux in a collimated beam from an incandescent lamp, at a color temperature of $2700 \mathrm{~K}$, to $5 \%$ of its original value (Griggs et al., 1989). Visual range (VR), another parameter to describe visibility, is defined in a similar way but with a $2 \%$ threshold. Following the Koschmieder approximation (Koschmieder, 1924) which connects the VR with $\beta_{\text {ext }}$ at $550 \mathrm{~nm}\left(\beta_{\text {ext }, 550}\right)$ neglecting the spectral variation of the extinction coefficient, MOR can be approximated as follows:

$\mathrm{MOR} \approx \frac{-\ln (0.05)}{\beta_{\mathrm{ext}, 550}} \approx \frac{3}{\beta_{\mathrm{ext}, 550}}$.

\subsubsection{FS11 Vaisala scatterometer}

The Vaisala FS11 scatterometer is a commercially available instrument to measure the MOR (Vaisala, 2010). It consists of a transmitter which transmits via an LED a pulsed nearinfrared light beam with a peak wavelength of $875 \mathrm{~nm}$ (see Fig. 1, left). A lens is concentrating the beam at a small volume of air and a receiver is detecting the scattered photons in a distinct scatter angle $\left(42^{\circ}\right)$. Both optics are orientated downwards. The MOR measurement range includes $5 \mathrm{~m}$ to $75 \mathrm{~km}$. This corresponds to a measurable transmittance for $1 \mathrm{~km}$ light path of 0 to 0.961 (see upper limit in Fig. 5). The accuracy in MOR measurement is claimed by the manufacturer to be $10 \%$ up to $10 \mathrm{~km}$ and $25 \%$ above. The accuracy in transmittance is claimed to be $3 \%$ for a path length of $1 \mathrm{~km}$. A dirt compensation algorithm is implemented which promises the correction of systematic errors of dust deposition on the instrument: additional infrared LEDs and photodiodes measure the reflectance of the sensor windows from the inside of the sensor housing so that contamination can be detected. After several months of measurements the FS11 scatterometer has been characterized as a robust and compact instrument (Hanrieder et al., 2012). Low-maintenance demand due to infrequently required cleaning (about every 2-3 months at PSA), as well as low temperature and low wind sensitivity and low power consumption, led to the conclusion that this instrument is suitable for use at remote sites for solar resource assessment. The instrument is measuring the beam attenuation due to scatter processes and is not physically taking absorption e.g. by water vapor into account. Nevertheless, the response of the scatterometer resembles a (visible light band) transmissometer response in the typical range of weather conditions ( $\mathrm{T}$. Lauronen, personal communication, 2014). The manufacturer claims that the response of the FS11 has been tested, evaluated and verified with a transmissometer including a visible light band emitter at different locations around the world. Therefore the absorption effect is covered to a certain extent, according to the manufacturer, 


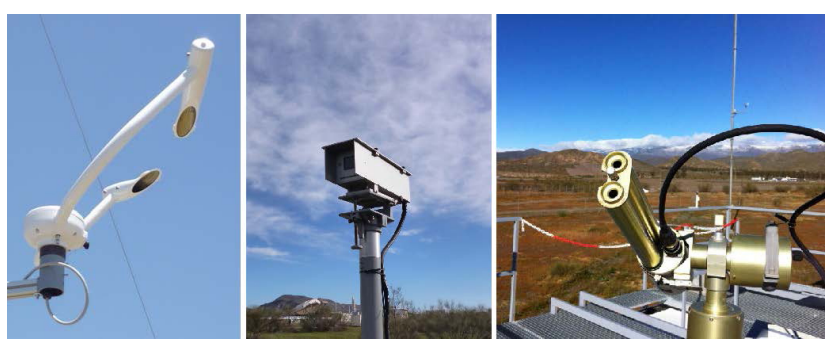

Figure 1. Left: scatterometer Vaisala FS11, center: long-path transmissometer Optec LPV4, right: sun photometer CIMEL.

but strongly absorbing phenomena have not been evaluated. Following the WMO standard (Griggs et al., 1989) and the according MOR definition, the transmissometer lamp should correspond to a white light beam source with a center wavelength of about $1070 \mathrm{~nm}$. We assume that the scatterometer is therefore calibrated to measurements based on a center wavelength of about $1070 \mathrm{~nm}$.

\subsubsection{Optec LPV4 transmissometer}

The long-path visibility transmissometer LPV4 of Optec (see Fig. 1, center) consists of a transmitter and a receiver unit. Both units can be mounted separately in a distance of up to $20 \mathrm{~km}$. At PSA the transmitter unit was located $485 \mathrm{~m}$ southeastwards to the receiver. The transmitter consists of a pulsed LED lamp which emits a peak wavelength of $532 \mathrm{~nm}$ with a band pass filter of $10 \mathrm{~nm}$ bandwidth (OPTEC, 2011). The receiver measures the modulated signal from the transmitter and samples signals at times when the transmitter lamp is off so that both signals can be subtracted. Many thousands of cycles are integrated so that background and turbulence noise is reduced. Therefore, the monochromatic transmittance is measured, which is not only lowered by scattering processes, but also by absorption. Although the peak wavelength of the instrument $(532 \mathrm{~nm})$ is located outside the main absorptions bands of water vapor, in the for CSP interesting broadband transmittance, water vapor plays an important role. It also has to be considered that aerosol spectral optical properties are a function of relative humidity (Skupin et al., 2014). The measurable MOR range lies between $458 \mathrm{~m}$ and $300 \mathrm{~km}$. This corresponds to a transmittance measurement range of 0.002 to 0.990 for $1 \mathrm{~km}$ slant range. For the LPV4 an accuracy of $3 \%$ in transmittance measurement is claimed by the manufacturer. For the chosen distance between transmitter and receiver unit at PSA, this results in an accuracy of around $6 \%$ for transmittances for a $1 \mathrm{~km}$ slant range (according to the derivation of Eq. 2).

\subsubsection{CIMEL sun photometer/AERONET}

The correction procedure (described in Sect. 2.3) is performed by including additional atmospheric on-site information. To do so, the measurements of PSA's AERONET station
(Aerosol Robotic NETwork) are used. The AERONET consists of ground-based sun photometer measurements (Holben et al., 1998) (see Fig. 1, right) and includes currently more than 600 stations worldwide. PSA's data sets are freely available at http://aeronet.gsfc.nasa.gov since February 2011 under the name Tabernas_PSA-DLR. Beside AOD (aerosol optical depth) measurements at eight different wavelengths between 340 and $1020 \mathrm{~nm}$, also total water vapor is provided. Angström parameters can be derived from the spectral AOD information. Data are available in three quality levels. Level 1.5 data, which are utilized in the correction procedure, are already automatically cloud screened (Smirnov et al., 2000).

\subsection{Radiative transfer model libRadtran}

Radiative transfer simulations in conjunction with the correction procedure are performed with the radiative transfer code libRadtran (library for radiative transfer) (Mayer and Kylling, 2005). The code is available via http://libradtran.org. Direct and global spectral irradiances in the desired height level can be simulated. For all simulations described in Sect. 2.3, the following adjustments are made: the spectral range of the simulation was chosen to be between 250 and $4000 \mathrm{~nm}$ with a resolution of $1 \mathrm{~nm}$. As radiative transfer solver, disort (discrete ordinate method) (Stamnes et al., 1988, 2000; Buras et al., 2011) was chosen as it is the default and recommended discrete ordinate code by the developers (Mayer et al., 2014). A pseudospherical geometry was invoked to account for spherical effects. A total of 16 streams were used to solve the radiative transfer equation. The distribution libRadtran 2.0 beta was used to take advantage of the newly developed gas absorption parameterization REPTRAN (Gasteiger et al., 2014) which is based on HITRAN molecular absorption data. The utilization of the REPTRAN parameterization is available in three different resolutions (fine: band width $=1 \mathrm{~cm}^{-1}$, medium and coarse 5 and $15 \mathrm{~cm}^{-1}$, respectively). REPTRAN medium reduces the computational time noticeable for the purpose of the absorption and broadband correction (ABC) procedure (see Sect. 2.3) but still provides the same band width resolution as formerly used correlated-k approximation LOWTRAN (Ricchiazzi et al., 1998) and is based on the even more precise HITRAN data.

Additionally, information about different atmospheric properties as the spectral AOD, ozone column and water vapor content can be included. Also, molecular or aerosol absorption or scattering can be switched off separately which is of special interest for the absorption correction (see Sects. 2.3.2 and 2.3.3).

\subsection{ABC - absorption and broadband correction}

The ABC (absorption and broadband correction) for visibility measurements focusses on the one hand on correcting the 
described FS11 Vaisala scatterometer measurement (details in Sect. 2.1.1) for missing consideration of the absorption. On the other hand it translates the monochromatic measurement of both, the scatterometer and the Optec LPV4 transmissometer (described in Sect. 2.1.2), into broadband transmittance which is the important parameter for CSP. The correction algorithm is a two-step procedure.

\subsubsection{Atmospheric transmission from sun to heliostat}

In a first step, a radiative transfer (RT) through the atmospheric column is performed with libRadtran (see Sect. 2.2). Gas profiles are adopted by the AFGL mid-latitude standard atmospheres by Anderson et al. (1986) chosen dependent on season and scaled linearly by on-site measurements; the ambient ground temperature $\left(T_{\mathrm{amb}}\right)$, pressure $(p)$ and relative humidity $(\mathrm{RH})$ are taken from a meteorological station at the site. The standard aerosol vertical profile by Shettle (1989), which is defined by a rural aerosol type in the boundary layer and background aerosol above $2 \mathrm{~km}$ height with a ground visibility of $50 \mathrm{~km}$ serves as the default setting. Additional information about longitude, latitude, altitude, the precipitable water vapor content, the spectral AOD for $500 \mathrm{~nm}$, the derived Ångström parameters and column ozone concentration by the nearby AERONET station scale the default profiles by Shettle (1989) in the case described in Sect. 3.1. In Sect. 3.2 the default aerosol profile of Shettle (1989) without any further scaling by AERONET measurement is used. In Sect. 3.3 a standard aerosol profile for an average continental condition is chosen as an expert guess of the aerosol distribution at PSA. The resulting radiation spectrum conduces as external, incoming radiation in the second step of the procedure.

\subsubsection{Atmospheric transmission between heliostat and receiver}

A homogeneous layer of $1 \mathrm{~km}$ depth is defined utilizing ground measurements of $T_{\mathrm{amb}}, p$ and RH. $1 \mathrm{~km}$ is chosen as this is a realistic distance between a heliostat and the receiver in a solar tower plant e.g. GEMAsolar (Torresol, 2014), PS20 (Abengoa, 2014) or IVANPAH (Brightsource, 2014). Other unknown parameters like the $\mathrm{O}_{2}, \mathrm{O}_{3}$, and $\mathrm{CO}_{2}$ densities are adopted (dependent on season and altitude) from the midlatitude standard atmospheres from Anderson et al. (1986). A second radiative transfer simulation (B1. in Fig. 2) is conducted through this layer using the spectral radiation output from step 1 as the initial spectral distribution. The spectral and broadband transmittance for this layer can be calculated from the transmitted DNI spectrum. In a third radiative transfer calculation (B2. in Fig. 2), the parameters are used, but the molecular and aerosol absorption effect is neglected.

\subsubsection{Absorption correction}

Atmospheric extinction is on the one hand caused by scattering and on the other hand by absorption processes by molecules and particles. The FS11 Vaisala scatterometer is considering the scatter contribution in its measurement but only partly the absorption (see Sect. 2.1.1). To model the distinct contributions of both effects, the second step of the correction procedure consists of radiative transfer calculations with (B1. in Fig. 2) and without (B2. in Fig. 2) including radiation attenuation caused by molecular and aerosol absorption.

Model results for each time step can be translated into a correction factor for the FS11 Vaisala scatterometer for the absorption effect FA 1 km,FS11 (C. in Fig. 2):

$\mathrm{FA}_{1 \mathrm{~km}, \mathrm{FS} 11}(t)=\frac{T_{1 \mathrm{~km}, \mathrm{bb}, \mathrm{sca}+\mathrm{abs}}(t)}{T_{1 \mathrm{~km}, \mathrm{bb}, \mathrm{sca}}(t)}$,

where $T_{1 \mathrm{~km}, \mathrm{bb}, \mathrm{sca}+\mathrm{abs}}(t)$ is the modeled broadband transmittance for $1 \mathrm{~km}$ slant range considering scattering and absorption processes, $T_{1 \mathrm{~km} \text {,bb,sca }}(t)$ is the modeled broadband transmittance only taken scattering into account and $\mathrm{FA}_{1 \mathrm{~km}, \mathrm{FS} 11}(t)$ is the resulting factor for absorption contribution to atmospheric extinction for the FS11 scatterometer

Taking into account the fact that absorption is partly resembled in the FS11 measurement due to the calibration with a transmissometer, the mean modeled absorption contribution is calculated and the measurement signal is only corrected for deviations from this average:

$\operatorname{CFA}_{1 \mathrm{~km}, \mathrm{FS} 11}(t)=\frac{\mathrm{FA}_{1 \mathrm{~km}, \mathrm{FS} 11}(t)}{\overline{\operatorname{FA}_{1 \mathrm{~km}, \mathrm{FS} 11}(t)}}$,

where $\mathrm{CFA}_{1 \mathrm{~km}, \mathrm{FS} 11}(t)$ is the absorption correction factor which is applied to the FS11 transmittance measurement signal (see Sect. 2.3.5).

The difference in broadband transmittance with and without taking absorption into account is displayed in Fig. 3 for 29 May 2013, 12:00:00 UTC. According to the sun photometer, an AOD for $500 \mathrm{~nm}$ of 0.05 was measured. In this case, absorption processes account for more than $6 \%$ of irradiance attenuation $\left(T_{1 \mathrm{~km}, \mathrm{bb}, \mathrm{sca}}-T_{1 \mathrm{~km}, \mathrm{bb}, \mathrm{sca}+\mathrm{abs}}=0.0608\right)$. This value varies with site and time, and therefore an according time-dependent correction factor has to be modeled.

\subsubsection{Broadband correction}

Both instruments, the scatterometer and the transmissometer, are based on nearly monochromatic measurements (875 and $532 \mathrm{~nm}$, respectively). Figure 3 shows the spectral dependency of atmospheric transmittance for 29 May 2013, 12:00:00 UTC. This example model result shows an about $3.4 \%$ higher transmittance for $875 \mathrm{~nm}$ compared to $532 \mathrm{~nm}$. As transmittance is spectrally dependent and for CSP broadband transmittance is of interest, this effect has to be corrected. To derive the correction factors for the spectrum and 


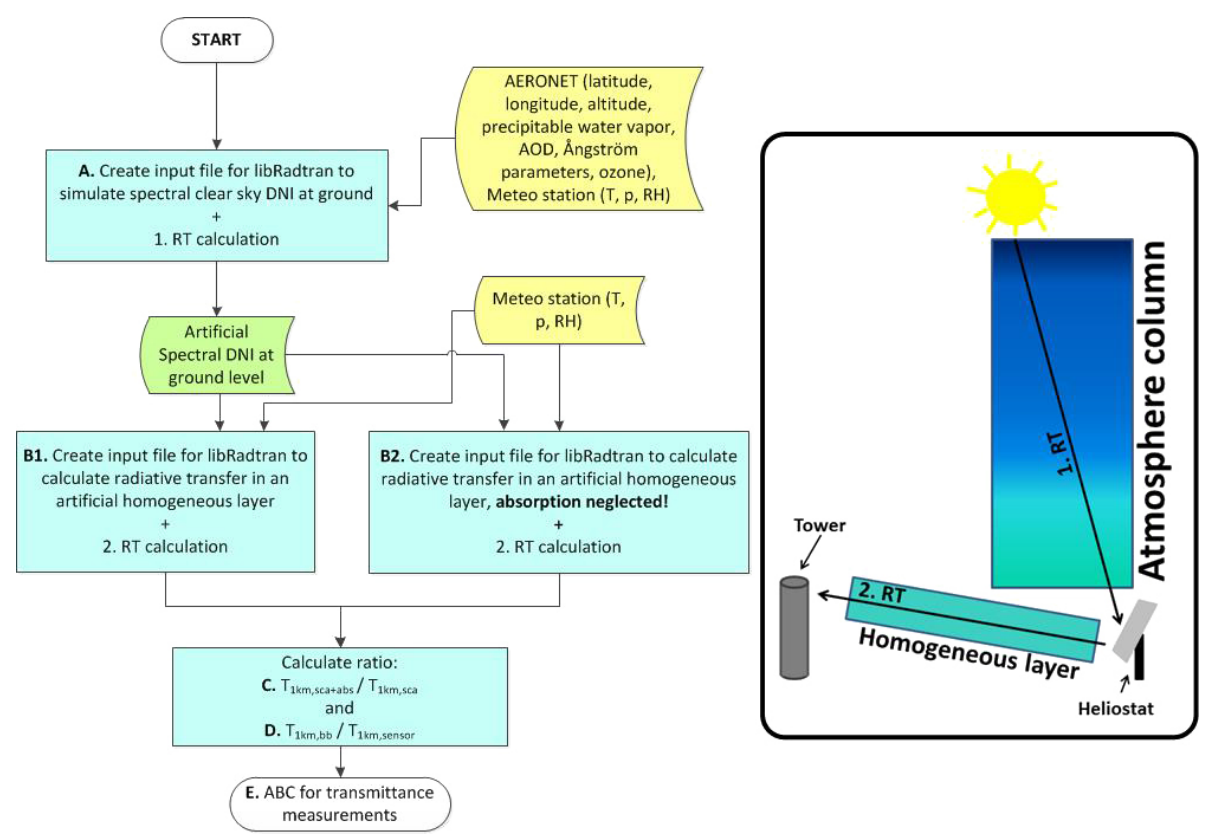

Figure 2. Right: sketch of two-stepped correction procedure for spectrum and absorption correction. Left: symbolic sketch of radiative transfer calculations through two layers.

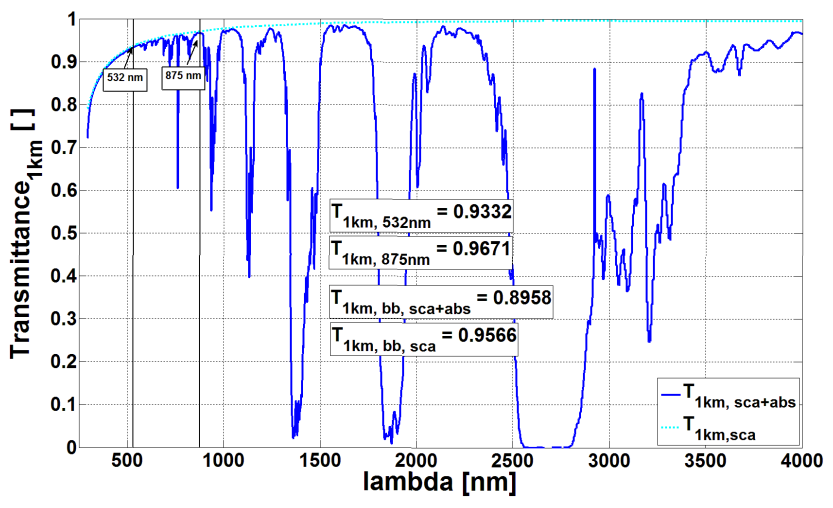

Figure 3. Spectral transmittance (blue, solid line) and spectral transmittance without absorption (cyan, dotted line) for a slant range of $1 \mathrm{~km}, 29$ May 2013, 12:00:00 UTC, PSA. Vertical lines show the location of the LPV4 transmissometer $(532 \mathrm{~nm})$ and the FS11 scatterometer $(875 \mathrm{~nm})$ measuring wavelengths.

for each instrument, the following ratio is calculated (D. in Fig. 2):

$\mathrm{CFB}_{1 \mathrm{~km} \text {,sensor }}(t)=\frac{T_{1 \mathrm{~km}, \mathrm{bb}}(t)}{T_{1 \mathrm{~km}, \text { sensor }}(t)}$.

In the case of the FS11, $T_{1 \mathrm{~km} \text {, sensor }}(t)$ is the modeled monochromatic transmittance for a slant range of $1 \mathrm{~km}$ and $1070 \mathrm{~nm}$ (the wavelength we assume the FS11 is calibrated

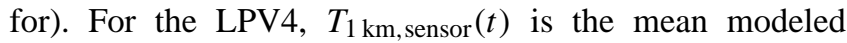
monochromatic transmittance for a slant range of $1 \mathrm{~km}$ and the wavelength range of $532 \pm 10 \mathrm{~nm}$ (according to the spec- ifications of the instrument). $T_{1 \mathrm{~km}, \mathrm{bb}}(t)$ describes the modeled broadband transmittance and $\mathrm{CFB}_{1 \mathrm{~km} \text {,sensor }}(t)$ is the correction factor for the spectrum which has to be applied to the according transmittance measurements of timestamp $t$ and the sensor.

\subsubsection{Final correction}

The above-described factors result in a final absorption and broadband correction $(\mathrm{ABC})$ for each instrument $(\mathrm{E}$ in Fig. 2):

$$
\begin{aligned}
T_{1 \mathrm{~km}, \mathrm{cor}, \mathrm{LVP} 4}(t) & =T_{1 \mathrm{~km}, \mathrm{LPV} 4}(t) \cdot \mathrm{CFB}_{1 \mathrm{~km}, \mathrm{LPV} 4}(t) \\
T_{1 \mathrm{~km}, \mathrm{cor}, \mathrm{FS} 11}(t) & =T_{1 \mathrm{~km}, \mathrm{FS} 11}(t) \\
& \cdot \mathrm{CFA}_{1 \mathrm{~km}, \mathrm{FS} 11}(t) \cdot \mathrm{CFB}_{1 \mathrm{~km}, \mathrm{FS} 11}(t) .
\end{aligned}
$$

Figure 4 shows the average correction factors $\mathrm{CFB}_{1 \mathrm{~km}, \mathrm{LPV} 4}$, $\mathrm{CFA}_{1 \mathrm{~km}, \mathrm{FS} 11}$ and $\mathrm{CFB}_{1 \mathrm{~km}, \mathrm{FS} 11}$ for the $\mathrm{ABC}$ procedure discussed in Sect. 3.1. The mean correction factors are displayed dependent on solar zenith angle (sunrise until solar noon to the left and solar noon until sunset to the right). While the LPV4 is corrected with a factor $\left(\mathrm{CFB}_{1 \mathrm{~km}, \mathrm{LPV} 4}\right)$ in between 0.98 and 1.02, the FS11 is corrected with factors between 0.93 and $0.99\left(\mathrm{CFA}_{1 \mathrm{~km}, \mathrm{FS} 11} \cdot \mathrm{CFB}_{1 \mathrm{~km}, \mathrm{FS} 11}\right)$.

\section{Results and discussion}

Measurement data of the FS11 scatterometer as well as the LPV4 transmissometer from May 2013 to May 2014 are analyzed. MOR measurements are averaged to a time resolu- 


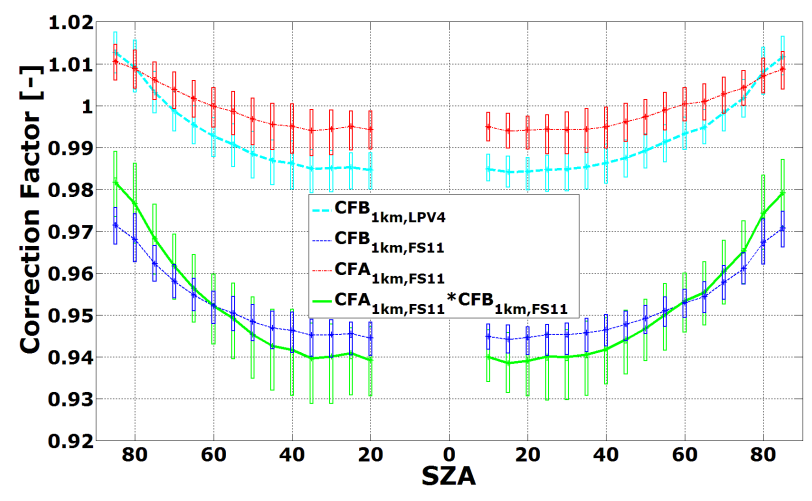

Figure 4. Mean behavior of correction factors (for case described in Sect. 3.1) $\mathrm{CFB}_{1 \mathrm{~km}, \mathrm{LPV} 4}$ for LPV4, CFB $1 \mathrm{~km}, \mathrm{FS} 11, \mathrm{CFA}_{1 \mathrm{~km}, \mathrm{FS} 11}$ and the total correction product $\mathrm{CFA}_{1 \mathrm{~km}, \mathrm{FS} 11} \cdot \mathrm{CFB}_{1 \mathrm{~km}, \mathrm{FS} 11}$ for FS11 dependent on SZA. Bars display $68.3 \%$ of all data points.

tion of $10 \mathrm{~min}$. Corresponding correction factors are modeled with a resolution of $1 \mathrm{~h}$, linearly interpolated to $10 \mathrm{~min}$ resolution and applied to the raw data. For better comparison, measurements of MOR are translated into transmittances for a slant range of $1 \mathrm{~km}\left(T_{1 \mathrm{~km}}\right)$, see Eqs. (1) and (2). Measurement data cover 35700 data points which corresponds to almost 248 complete days. Other data points were excluded from the analysis because of sensor cleaning or other documented disturbances. Not regarding measurements which have been conducted during night, early mornings or evenings (solar zenith angles $>85^{\circ}$ ) result in 15137 available data points to be corrected for the time period from May 2013 to May 2014. Simulations for solar zenith angles larger than $85^{\circ}$ are not conducted as those time periods are not of interest for CSP plant operators. Therefore the modeled correction factors are limited to smaller angles (see Fig. 5). Figure 5 shows the intercomparison of the FS11 and the LPV4 transmittance measurement. Mean deviation between both sensor measurements accounts for about $4.4 \%$ with a RMSE of $12.2 \%$.

Outlier data points for which the transmittance measured by the FS11 is exceeding the LPV4 measurement might be explained by local disturbances. While the FS11 is located in the northeast of the PSA, the LPV4 is mounted in the south. Additionally, the distance between transmitter and receiver unit and therefore the sampled air volume is small for the FS11 compared to the LPV4 which is mounted with a horizontal distance of about $485 \mathrm{~m}$ between the transmitter and the receiver. The LPV4 is therefore also more sensitive to local disturbances as for example dust plumes being transported through the sampled air volume by passing by cars.

\subsection{Absorption and broadband correction with information about on-site aerosol conditions}

This presented $\mathrm{ABC}$ procedure is utilizing on-site measurements of $T_{\mathrm{amb}}, p, \mathrm{RH}$ by a meteorological measurement sta-

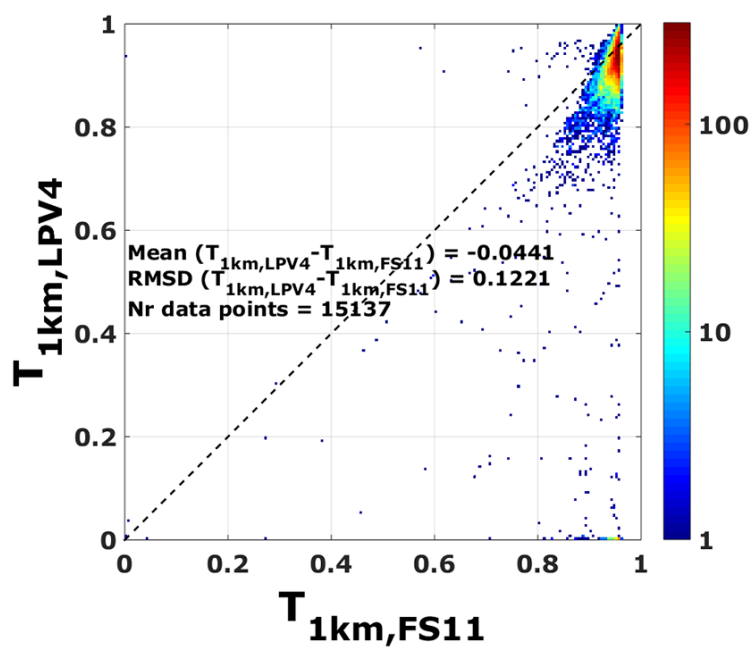

Figure 5. Uncorrected transmittance for $1 \mathrm{~km}$ slant range measured by FS11 scatterometer and LPV4 transmissometer without application of the ABC. Time steps with solar zenith angles of more than $85^{\circ}$ are excluded. Color distribution displays the number of data points per grid point (logarithmic color scale).

tion. Additionally, information about the spectral AOD as well as ozone and water vapor column concentration measured by the nearby CIMEL sun photometer is included to optimize the correction results and to display the on-site aerosol conditions as good as possible.

The result of the $\mathrm{ABC}$ procedure applied to the raw transmittance measurements from Fig. 5 is shown in Fig. 6. The mean difference between the corrected FS11 and the corrected LPV4 signal is reduced from 4.4 to $0.6 \%$. The mean RMSE (root mean square error) between both corrected data sets is only slightly lowered (12.2 vs. $11.4 \%$ ).

While the average uncorrected transmittance for $1 \mathrm{~km}$ slant range monitored by the FS11 scatterometer is $94.5 \%$, the LPV4 transmissometer measures a mean uncorrected transmittance $T_{1 \mathrm{~km}}$ of $90.1 \%$ (for solar zenith angles $<85^{\circ}$ ). After correction of the 15137 data points, the average transmittances account to 90.1 and $89.5 \%$, respectively (see Table 1). Outliers which display lower transmittances derived from the FS11 measurements compared to the LPV4 measurement can be explained by the different sensitivity of the instruments to local disturbances as explained earlier.

The monochromatic measuring instrument LPV4 works with a band pass filter of about $10 \mathrm{~nm}$ in the visible spectral region. Therefore, main absorption bands (e.g. of water vapor) will not be considered and will not reduce the measurement signal (see also example in Fig. 3). But this reduction plays an important role in the for CSP interesting broadband transmittance. Hence, the effect of spectrally correcting the raw LPV4 signal to lower transmittances by about $0.6 \%$ is compensating this systematic error due to absorption. The same is also true for the spectral correction of the FS11 scat- 


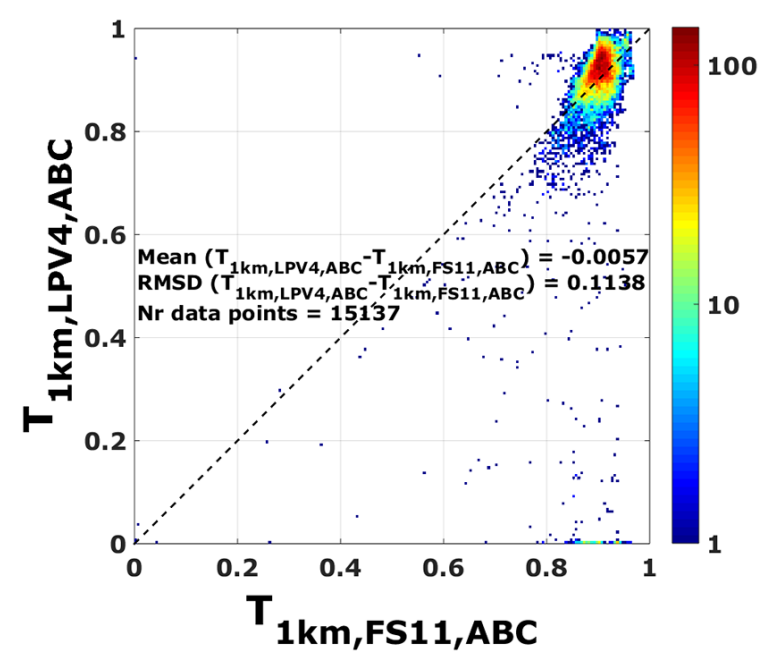

Figure 6. Absorption and broadband-corrected transmittance for $1 \mathrm{~km}$ slant range measured by FS11 scatterometer and LPV4 transmissometer. Color distribution displays the number of data points per grid point (logarithmic color scale).

terometer while here an additional factor, the lack of information about absorption which is also corrected, is added.

\subsection{Absorption and broadband correction for a non-site specific standard atmosphere}

Unlike in Sect. 3.1, in this evaluation no information from the nearby CIMEL sun photometer is included in the first step of the ABC procedure which is the simulation the transmission between the sun and the heliostat. As sun photometer data might not be available on every site of interest or every according demanded solar-resource assessment, this section presents the results conducted with the ABC procedure without considering on-site sun photometer measurements. Precipitable water vapor content, the spectral AOD for $500 \mathrm{~nm}$ and column ozone concentration are defined by the chosen AFGL mid-latitude standard atmospheres by Anderson et al. (1986) and the standard aerosol profile by Shettle (1989). $T_{\mathrm{amb}}, p$ and $\mathrm{RH}$ are still taken from on-site measurements.

Figure 7 displays the corrected transmittance for a slant range of $1 \mathrm{~km}$ and measured with the FS11 scatterometer and the LPV4 transmissometer. Noticeable is the higher mean difference between both corrected signals $(0.8 \%)$ compared to the results presented in Sect. 3.1 (0.6\%, respectively). The mean RMSE (11.4\%) is about the same as in Sect. 3.1 .

After the correction without the additional input of AERONET data, a mean $T_{1 \mathrm{~km}}$ of $90.3 \%$ can be calculated for the FS11 while the LPV4 shows a mean value of $89.5 \%$ (see Table 1).

This findings show that the application of the ABC procedure without additional AERONET input also results in satisfying coincidence between both corrected data sets.

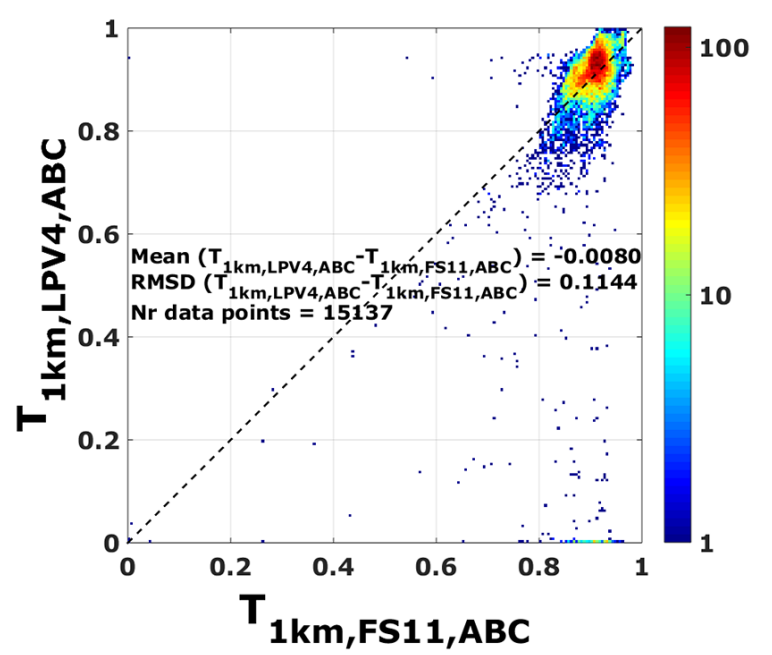

Figure 7. Absorption and broadband-corrected transmittance for $1 \mathrm{~km}$ slant range measured by FS11 scatterometer and LPV4 transmissometer. No sun photometer input in ABC procedure. Color distribution displays the number of data points per grid point (logarithmic color scale).

The mean small difference between average $T_{1 \mathrm{~km}}$ with and without additional input of AERONET data indicates that the default aerosol composition and profile defined by Shettle (1989), which is utilized instead of exploiting the AERONET information, does not perfectly fit the on-site situation at PSA. Nevertheless, this standard profile is describing the on-site aerosol situation quite well. This only accounts for PSA and might not be the case for other sites.

\subsection{Absorption and broadband correction using an expert guess aerosol type}

The default setting of libRadtran for the aerosol profile according to Shettle (1989) fits quite well the situation at PSA what can be seen in Sect. 3.2. As this might not be the case for other sites, an expert guess can be applied which includes assumptions about most probable aerosol type contribution and height distribution for the site to enhance the performance of the $\mathrm{ABC}$ procedure without additional AERONET measurements. Therefore, further evaluation of the ABC procedure is conducted by customizing the aerosol profile: LibRadtran provides typical optical properties of aerosols and their vertical distribution calculated based on refractive indices and size distributions of the software package OPAC (Hess et al., 1998; Emde et al., 2010). Comparing mean Ångström parameters and optical depths of the nearby AERONET station for 2012 and 2013 with the given values for the standard aerosol profiles, the "continental average" aerosol profile displays the best fit to the local conditions. The profile represents remote continental areas and consists mainly of an increased amount of soluble and insoluble aerosol components together with a small soot contribution to describe 
Table 1. Average transmittance for $1 \mathrm{~km}$ slant range before and after ABC (for spectrum 250-4000nm).

\begin{tabular}{lrrrr}
\hline No correction & $\begin{array}{r}\text { ABC with } \\
\text { AERONET data }\end{array}$ & $\begin{array}{r}\text { ABC without } \\
\text { AERONET data }\end{array}$ & $\begin{array}{r}\text { ABC with OPAC } \\
\text { continental average } \\
\text { aerosol profile }\end{array}$ \\
\hline$T_{1 \mathrm{~km}, \mathrm{FS} 11}$ & $94.51 \%$ & $90.05 \%$ & $90.28 \%$ & $89.94 \%$ \\
$T_{1 \mathrm{~km}, \mathrm{LPV} 4}$ & $90.10 \%$ & $89.48 \%$ & $89.49 \%$ & $89.14 \%$ \\
\hline
\end{tabular}

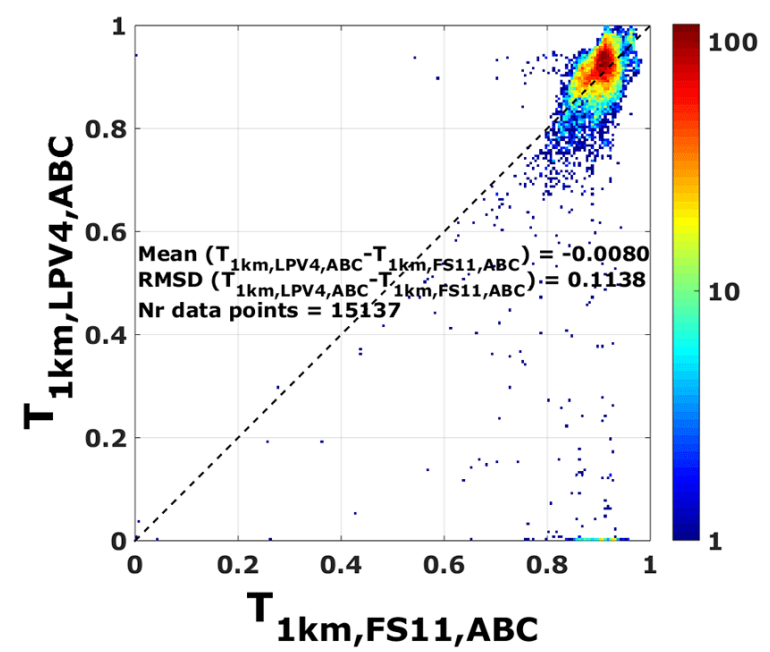

Figure 8. Absorption and broadband-corrected transmittance for $1 \mathrm{~km}$ slant range measured by FS11 scatterometer and LPV4 transmissometer. Input of standard aerosol profile "continental average" in $\mathrm{ABC}$ procedure. Color distribution displays the number of data points per grid point (logarithmic color scale).

the anthropogenic influence. Alternatively, also other available data sets which include aerosol information for example from satellite retrievals or regional models can be included to choose a best fitting standard aerosol profile.

Figure 8 displays the corrected transmittance measurements of the scattero- and transmissometer. In comparison to results of the evaluation conducted in Sect. 3.1, a mean difference between both corrected signals of $0.8 \%$ is achieved. This is around $0.02 \%$ higher than the results from Sect. 3.1. The mean RMSE (11.4\%) is virtually the same as in Sect. 3.1. This result shows a similar coincidence with the results conducted with additional input of sun photometer data compared to the results of Sect. 3.2.

The mean corrected transmittance for the scatterometer and the transmissometer are 89.9 and $89.1 \%$, respectively. These results indicate that the standard average continental aerosol profile similarly fits the actual situation at PSA compared to the standard aerosol profile by Shettle (1989).

The results show that the $\mathrm{ABC}$ procedure improves the coincidence between both instruments even without accessible sun photometer data. In this case, careful selection of as- sumptions about atmospheric parameters like spectral AOD or water vapor content is recommended.

\subsection{Validation using model simulation}

Another approach to determine atmospheric extinction is presented here which includes libRadtran simulations which have been performed using the given settings from Sect. 2.2, 2.3.1 and 2.3.2 for a temporal resolution of $1 \mathrm{~h}$. The calculations simulate the spectral transmittance at surface level by using only on-site measurements of $T_{\mathrm{amb}}, p$ and RH as well as information about the aerosol amount of a CIMEL sun photometer. The results are compared to the ABC-corrected FS11 and LPV4 measurements from Sect. 3.1 and are shown in Figs. 9 and 10.

Figure 9 displays the result comparing the absorption- and broadband-corrected FS11 measurements with the model simulations. A mean difference of $2.8 \%$ with a mean RMSE of $4.8 \%$ is calculated. Due to lack of knowledge, a standard aerosol particle mixture is considered which is defined to be a rural aerosol consisting of around $70 \%$ of water-soluble aerosol particles and $30 \%$ dust particles (see Shettle, 1989). This assumption might not fit well for the investigated time period. Another cause might be local disturbances which the FS11 (and also the LPV4 measurement) suffers from while the sun photometer is not affected.

Figure 10 displays the comparison of the broadbandcorrected LPV4 measurement with the modeled simulation. A mean difference between both data sets of $3.4 \%$ and a mean RMSE of $12.7 \%$ can be determined. The corrected LPV4 measurement depicts smaller transmittances for several time steps than the according simulation. This might be mainly caused by the LPV4 measurement uncertainty (see Sect. 3.5).

These results show that the simulation approach which just uses sun photometer and common meteorological data represents the on-site atmospheric extinction quite well. Anyway, specified settings about the state of the atmosphere, e.g. the aerosol height profile have to be chosen carefully (Hanrieder et al. 2015).

\subsection{Uncertainty analysis}

An uncertainty analysis for the FS11 scatterometer as well as the LPV4 transmissometer measurement and the according $\mathrm{ABC}$ method is performed. According to the principle of the 


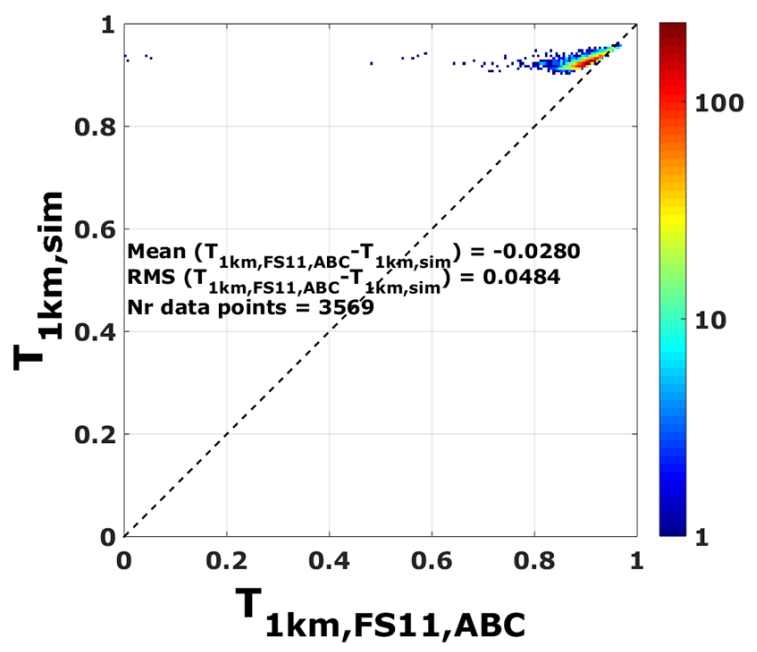

Figure 9. Modeled transmittance for $1 \mathrm{~km}$ slant range compared with absorption- and broadband-corrected transmittance as in case of Sect. 3.1 measured by FS11 scatterometer. Color distribution displays the number of data points per grid point (logarithmic color scale).

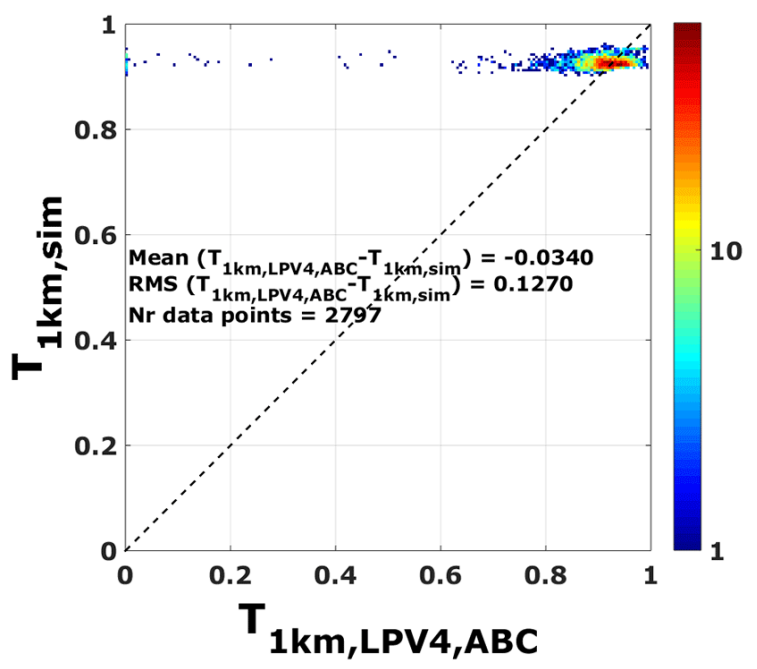

Figure 10. Modeled transmittance for $1 \mathrm{~km}$ slant range compared with absorption- and broadband-corrected transmittance as in case of Sect. 3.1 measured by LPV4 transmissometer. Color distribution displays the number of data points per grid point (logarithmic color scale).

Gauß error propagation, the overall uncertainty due to the measurement of both instruments and the ABC method can be estimated. In both cases, the total uncertainty for $T_{1 \mathrm{~km}}$ is a superposition of the uncertainty of the measurement and the ABC method:

$\mathrm{u}_{T_{1 \mathrm{~km}}}=\sqrt{\left(\mathrm{u}_{T_{1 \mathrm{~km}, \text { meas }}}\right)^{2}+\left(\mathrm{u}_{T_{1 \mathrm{~km}, \mathrm{ABC}}}\right)^{2}}$.

The FS11 measures MOR and the uncertainty in MOR measurement given by the manufacturer is 0.1 for MOR up to
$10 \mathrm{~km}$ and 0.2 for higher MOR. As this steep rise of uncertainty at $10 \mathrm{~km}$ is a rather unrealistic assumption, a linear increase of uncertainty from 0.1 to 0.2 between 5 and $10 \mathrm{~km}$ is assumed. Further calculations make use of this assumption. To determine the uncertainty $\mathrm{u}_{T_{1 \mathrm{~km} \text {,meas }}}$ of the FS11 measurement, Eq. (2) can be used to derive the uncertainty for the transmittance (for a slant range of $x$ ) by assuming its validity for the broadband solar spectrum:

$\frac{\partial \mathrm{MOR}}{\partial T_{x}}=-\frac{\mathrm{MOR}}{\ln \left(T_{x}\right)} \cdot \frac{1}{T_{x}}$.

Therefore, the relative uncertainty of MOR $\left(\mathrm{u}_{\mathrm{MOR}}\right)$ is connected to the relative uncertainty of $T_{1 \mathrm{~km}}\left(\mathrm{u}_{T_{1 \mathrm{~km}, \mathrm{FS} 11, \text { meas }}}\right)$ with the following formula:

$\mathrm{u}_{T_{1 \mathrm{~km}, \mathrm{FS} 11, \mathrm{meas}}}=-\mathrm{u}_{\mathrm{MOR}} \cdot \frac{1 \mathrm{~km} \cdot \ln (0.05)}{\mathrm{MOR}}$.

Equation (10) shows that the lower the measured MOR (and therefore $T_{1 \mathrm{~km}}$ ) and with a fixed relative uncertainty in MOR, the higher is also the relative uncertainty in $T_{1 \mathrm{~km}}$. The effects of assumptions about the scattering phase function, the missing consideration of the absorption effect and the small air sample volume should be included in the uncertainty statement of Vaisala. The same accounts for the dirt compensation algorithm, the LED intensity stabilizing algorithm, the calibration and calibration check accuracy and the external radiation hitting the receiver photo-diode. Additionally, experiments have been performed to study effects like contamination or external radiation which showed that they can be neglected in the uncertainty analysis (see Table 2).

To calculate the uncertainty of the LPV4 measurement $\left(\mathrm{u}_{T_{1 \mathrm{~km} \text {.LPV4,meas }}}\right)$, the uncertainty in the calibration constant CAL and the calibration constant drift over time have to be considered. The according formula to calculate CAL during the calibration process and the uncertainty levels of each component are given in OPTEC (2011). The relative uncertainty of CAL $\left(\mathrm{u}_{\mathrm{CAL}}\right)$ is calculated to be 0.015 . Including the drift of the calibrations constant $\mathrm{u}_{\mathrm{CAL}}$ is 0.028 . The according relative uncertainty of $T_{1 \mathrm{~km}}$ depends on $T_{1 \mathrm{~km}}$. Additionally, the larger the distance between transmitter and receiver, the lower the uncertainty of the LPV4 measurement. Several other influences can cause an additional rise in uncertainty of the LPV4 measurement and have been investigated in different experiments: window contamination, temperature sensibility of transmitter and receiver, misalignment, light source variations and external radiation. According uncertainties are listed in Table 2.

The uncertainties of the ABC method for the FS11 and LPV4 $\left(u_{T_{1 \mathrm{~km}, \mathrm{FS} 11, \mathrm{ABC}}}\right.$ and $\left.\mathrm{u}_{T_{1 \mathrm{~km}, \mathrm{LPV} 4, \mathrm{ABC}}}\right)$ is influenced by several assumptions (all derived relative uncertainties are listed in Table 2):

- Aerosol type and AOD - Due to lack of knowledge about the type, mixture and height profile of the present 
Table 2. Calculated and estimated relative uncertainties for FS11 and LPV4 measurements and the ABC method.

\begin{tabular}{llrr}
\hline & Rel. uncertainty for $T_{1 \mathrm{~km}}$ due to: & FS11 & LPV4 \\
\hline Measurement: & contamination & 0 & 0.014 \\
& system temperature, misalignment, & 0 & 0 \\
light source, external radiation & dependent on $T_{1 \mathrm{~km}}(0-0.2)$ & dependent on $T_{1 \mathrm{~km}}(0-0.2)$ \\
& aerosol type $:$ & 0.0002 & 0.0001 \\
& AOD & 0.0055 & 0.0059 \\
& $T_{\text {amb }, p, \mathrm{RH}}$ & 0.0035 & 0.0035 \\
& PWV & 0.0045 & 0.0045 \\
& homogeneous layer and location & 0.0008 & 0.0008 \\
& spectrum & 0.032 & - \\
& absorption correction & 0.006 & 0.0001 \\
broadband correction & dependent on $T_{1 \mathrm{~km}}$ & dependent on $T_{1 \mathrm{~km}}$ \\
\hline
\end{tabular}

aerosol, the default option is applied. To estimate the uncertainty of the $\mathrm{ABC}$ method due to the choice of the aerosol type in the simulations, two extreme cases have been simulated for May 2013 to May 2014 which consider in one case only mineral dust particles and in the other case only sea salt particles. The relative uncertainty depends on $T_{1 \mathrm{~km}}$ according to this test and ranges from 0 up to 0.2 . To estimate the uncertainty introduced to the $\mathrm{ABC}$ method due to uncertain AOD measurements by the sun photometer, the method was tested considering the uncertainty of 0.02 (Holben et al., 1998) for 11 March 2014 until 23 March and a 10 min temporal resolution. In this test, the AOD level of the libRadtran simulation was once increased by 0.02 and once decreased. The mean difference in transmittance between both simulation scenarios was calculated. This difference was interpreted as the relative uncertainty which was then determined to be $0.02 \%$ for the FS 11 and $0.01 \%$ for the LPV4.

- Atmosphere - In both RTs, the AFGL mid-latitude standard atmospheres by Anderson et al. (1986) have been applied. Not only on-site measurements of $T_{\mathrm{amb}}, p$ and $\mathrm{RH}$ are used to scale the standard profile but also the precipitable water vapor (PWV). Corresponding simulations for assumed uncertainties of $0.9^{\circ} \mathrm{K}, 2 \mathrm{hPa}, 4$ and $0.15 \%$ (see Campbell Scientific, 2007, 2010; Holben et al., 1998; Perez-Ramirez et al., 2014), respectively, have been performed for the same 12-day period to derive the relative uncertainty $(0.55$ and $0.59 \%$ for FS 11 and LPV4, respectively).

- Homogeneous layer and location - In the second RT from heliostat to the receiver, a horizontal and vertical homogeneous layer is defined. The layer was defined as homogeneous for the aerosol profile as well as the atmospheric parameters. As the FS11 and LPV4 are not located exactly at the same location this assumption might not be completely valid. Comparisons between two FS11 mounted at different locations and heights above ground at PSA showed that the mean difference between both measurements is around $0.4 \%$ which can be translated in the relative uncertainty for $T_{1 \mathrm{~km}}$ for both the FS11 and LPV4.

- Spectrum - In this publication, we intended to keep the results independent on specific design and material of the heliostats and the receiver. For a plant simulation, the specific heliostat reflectance might play a role in the MOR correction. It is well known (see for example Meyen et al., 2009) that the spectral reflectance of mirrors is not constant and dependent on the coating of the mirror. The spectral irradiance between 2500 and $4000 \mathrm{~nm}$ accounts for less than $1 \%$ for the atmospheric conditions from ASTM G173 and all air masses. The calculated transmittance for this wavelength interval and non-zero spectral DNI is not zero. If one would calculate the broadband transmittance for the wavelength interval from 250 to $2500 \mathrm{~nm}$ and for the whole investigated period, it would result in a mean difference of $0.08 \%$. The relative uncertainty in transmittance due to the spectrum is therefore estimated to be $0.08 \%$ compared to calculations for the range 250 to $4000 \mathrm{~nm}$. Furthermore the reflectance of the heliostat is also not zero, but around $10 \%$ above $3000 \mathrm{~nm}$ (between 2500 and $3000 \mathrm{~nm}$ almost no spectral DNI present). Hence, the effect of the heliostat reflectivity will be much smaller than $1 \%$. Therefore, the correction algorithm will deliver nearly the same result even if the heliostat's spectral reflectance is considered. For the verification of the method the heliostat reflectance doesn't have to be considered. The effect due to the spectral absorptance of the receiver can be in comparison to the effect caused by the heliostat reflectance, for the current state of the art, neglected. 
- Absorption correction - We assume that the postprocessing software of the FS11 already includes indirectly the mean absorption effect as the instrument and the software were developed based on a comparison with a transmissometer which used a visible light band. Strong absorption events might not be displayed with sufficient accuracy, and therefore only the deviation from the mean absorption effect is corrected. If the absorption effect would be corrected entirely for the period of May 2013 until May 2014 instead of only the deviation from the mean effect for the whole time period, the mean corrected FS11 measurements of $T_{1 \mathrm{~km}}$ would result about $2.92 \%$ higher. The relative uncertainty for the FS11 can therefore be estimated to be 0.032 for a mean $T_{1 \mathrm{~km}}$ equal 0.901 . For the LPV4, no uncertainty is introduced by this effect.

- Broadband correction - The approximation of the ABC uncertainty due to the broadband correction for the FS11 was performed by assuming the measurement result to display the transmittance at $875 \mathrm{~nm}$ (actual wavelength of the FS11) instead of $1070 \mathrm{~nm}$ for May 2013 until May 2014. To approximate the ABC uncertainty due to the broadband correction for the LPV4, the correction of the LPV4 with the corresponding ratio between the exact wavelength of the instrument $(532 \mathrm{~nm})$ and the simulated broadband transmittance instead of using the mean value for $532 \pm 10 \mathrm{~nm}$ was performed and compared to the initial approach.

The total absolute uncertainties $\mathrm{u}_{T_{1 \mathrm{~km}, \mathrm{FS} 11}}$ and $\mathrm{u}_{T_{1 \mathrm{~km}, \mathrm{LPV} 4}}$ are shown in Fig. 11. The absolute uncertainty due to the measurement of the LPV4 decreases for decreasing transmittance. The measurement uncertainty of the FS11 increases from $T_{1 \mathrm{~km}}$ equals 1 to 0.64 . The absolute uncertainty due to the ABC method has its maximum at $T_{1 \mathrm{~km}}$ of about 0.55 for both sensors and so does the total absolute uncertainty. The total absolute uncertainty of the LPV4 exceeds that of the FS11 for $T_{1 \mathrm{~km}}$ of 1 to about 0.78 . For lower $T_{1 \mathrm{~km}}$ the uncertainty of the FS11 is higher. For $T_{1 \mathrm{~km}}$ equal to 0.9 , an absolute uncertainty of about 0.038 is expected for the FS11 and about 0.057 for the LPV4. The combined absolute uncertainty ( 0.068 for $T_{1 \mathrm{~km}}$ equal to 0.9 ) justifies quite well the mean RMSE between both corrected data sets as presented in Sect. 3.1. To estimate the absolute uncertainty of the results for yearly averages, it can be assumed that the introduced uncertainty by the assumption of the aerosol type, the homogeneous layer and location as well as the uncertainties in measurements in $T_{\mathrm{amb}}, p$, RH and PWV and the absorption correction is averaged out over the whole year. For $T_{1 \mathrm{~km}}$ equal to 0.9 , resulting absolute uncertainties of 0.020 and 0.054 are therefore estimated for the FS11 and the LPV4, respectively.

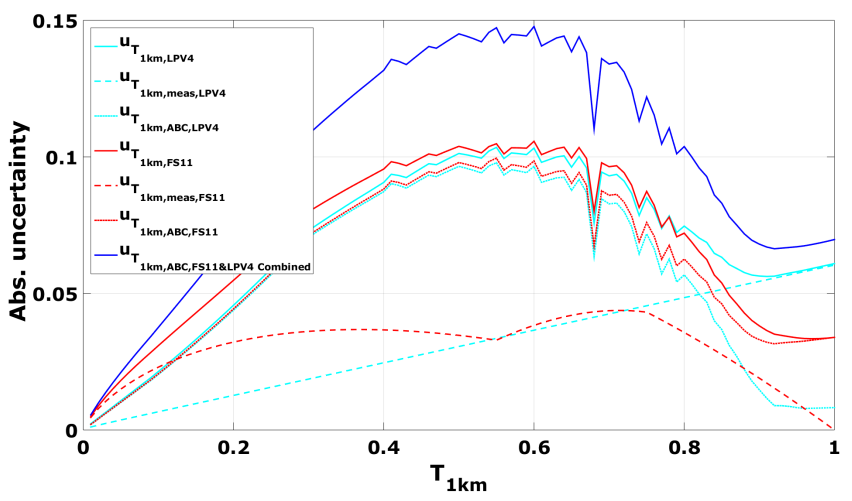

Figure 11. Absolute uncertainties of absorption- and broadbandcorrected transmittance as in case of Sect. 3.1 measured by FS11 scatterometer and LPV4 transmissometer.

\section{Conclusion and outlook}

Atmospheric extinction is a crucial factor in plant yield assessment and plant optimization of solar tower plants. It can vary strongly with site and time. Two commercially available instruments which are measuring indirectly the atmospheric transmittance are selected. These instruments, the Vaisala FS11 scatterometer and the Optec LPV4 transmissometer, are both based on a monochromatic measurement principle. As the solar spectrum undergoes a certain diurnal and annual cycle this must be accounted for due to the spectral dependence of the instruments. The scatterometer is additionally considering the atmospheric absorption only indirectly to a certain extent due to the calibration process and is excluding strongly absorbing phenomena.

A correction method concerning mentioned limitations of these instruments was developed. The absorption and broadband correction $(\mathrm{ABC})$ consist of different radiative transfer calculations conducted with libRadtran (Mayer and Kylling, 2005) to simulate time-dependent spectral transmittance. Additional input of sun photometer data into the procedure is possible. A data set conducted at the Plataforma Solar de Almería (PSA) spanning measured transmittances data from May 2013 to May 2014 was evaluated.

The $\mathrm{ABC}$ procedure including additional information about the atmosphere from sun photometer measurement results in an improved coincidence of the scatterometer and the transmissometer data by a factor of 7.74 (mean difference of raw data: $4.41 \%$, mean difference of data after $\mathrm{ABC}$ : $0.57 \%$ ). Mean monochromatic transmittances for a slant range of $1 \mathrm{~km}$ for the whole time period is calculated for the uncorrected data to be 94.51 and $90.10 \%$ for the scatterometer and the transmissometer, respectively. Applying the $\mathrm{ABC}$ procedure lowers the derived mean broadband transmittances to 90.05 and $89.48 \%$.

As sun photometer data might not be available on every site of interest, the evaluation of the $\mathrm{ABC}$ without in- 
putting additional information from a sun photometer was conducted. Depending on the chosen aerosol conditions, this approach still shows an improved coincidence $(0.80 \%$ for a standard aerosol profile according to Shettle (1989), $0.80 \%$ for the standard average continental aerosol profile according to OPAC, Hess et al., 1998; Emde et al., 2010) between the two sensors. Therefore, careful selection of assumptions about the atmosphere depending on the site and time is improving the performance of the $\mathrm{ABC}$ procedure.

Further, a simulation approach which just uses sun photometer and common meteorological data to determine the on-site atmospheric extinction at surface is presented. The validation of corrected FS11 and LPV4 measurements with the simulation results shows a mean difference of 2.8 and $3.4 \%$, respectively. Assumptions about the aerosol profile in the simulations have to be chosen carefully.

An uncertainty analysis showed that for $T_{1 \mathrm{~km}}$ equal to 0.9 and a temporal resolution of $10 \mathrm{~min}$, an absolute uncertainty of about 0.038 is expected for the FS11 and about 0.057 for the LPV4. Combining both uncertainties results in an overall absolute uncertainty of 0.068 which justifies quite well the mean RMSE between both corrected data sets. For yearly averages several error influences average out and absolute uncertainties of 0.020 and 0.054 can be expected for the FS11 and the LPV4, respectively.

These findings are only valid for PSA. The ABC might result in different correction factors at other sites as the solar spectrum as well as molecular and aerosol absorption conditions will differ. The instruments might over- or underestimate actual atmospheric extinction without the according correction procedure. Therefore it is recommended to apply the $\mathrm{ABC}$ also for industrial purposes.

Further investigation about more precise atmospheric parameterization will be performed. Larger data sets and different sites will be evaluated to refine the procedure for global application.

Acknowledgements. The authors thank the Group of Atmospheric Optics, Valladolid University, for the provision of the CÆLIS tool (http://www.caelis.uva.es) used in this publication. We thank the AERONET, PHOTONS and RIMA staff for their support. The research leading to these results has received funding from the European Union Seventh Framework Programme (FP7/2007-2013) under grant agreement Nr. 262254 (ACTRIS). Agreement 262254.

The article processing charges for this open-access publication were covered by a Research Centre of the Helmholtz Association.

Edited by: U. Friess

\section{References}

Abengoa: available at: http://www.abengoasolar.com, last access: 15 January 2014.

AERONET: available at: http://aeronet.gsfc.nasa.gov, last access: 15 January 2014.

Anderson, G. P., Clough, S. A., Kneizys, F. X., Chetwynd, J. H., and Shettle, E. P.: AFGL Atmospheric Constituent Profiles (1$120 \mathrm{~km}$ ), Air Force Geophysics Laboratory Hanscom Air Force Base, Bedford, Mass., AFGL-TR-86-0110, 47 pp., 1986.

Ballestrín, J. and Marzo, A.: Solar radiation attenuation in solar tower plants, Sol. Energy, 86, 388-392, 2012.

Belhomme, B., Pitz-Paal, R., Schwarzbözl, P., and Ulmer, S. A new fast ray tracing tool for high-precision simulation of heliostat fields, J. Sol. Energ.-T. ASME, 131, 031002-1, doi:10.1115/1.3139139, 2009.

Brightsource: Available at: http://www.ivanpahsolar.com, last access: 15 January 2014.

Buck, R.: User Manual: Solar Power Raytracing Tool SPRAY, Technical report, DLR, 7-8, 2011.

Buras, R., Dowling, T., and Emde, C.: New secondary-scattering correction in DISORT with increased efficiency for forward scattering, J. Quant. Spectrosc. Ra., 112, 2028-2034, 2011.

Inc. Campbell Scientific: CS100 Barometric Pressure Sensor - Instruction Manual, 2007.

Inc. Campbell Scientific: CS215 Temperature and Relative Humidity Probe - Instruction Manual, 2010.

D'Almeida, G. A. and Schütz, L.: Number, mass and volume distribution of mineral aerosol and soils of the Sahara, J. Clim. Appl. Meteorol. 22, 233-243, 1983.

Emde, C., Buras, R., Mayer, B., and Blumthaler, M.: The impact of aerosols on polarized sky radiance: model development, validation, and applications, Atmos. Chem. Phys., 10, 383-396, doi:10.5194/acp-10-383-2010, 2010.

Gasteiger, J., Emde, C., Mayer, B., Buras, R., Bühler, S. A., and Lemke, O.: Representative wavelengths absorption parametrization applied to satellite channels and spectral bands, J. Quant. Spectrosc. Ra., 148, 99-115, 2014.

Gertig, C., Delgado, A., Hidalgo, C., and Ron, R.: SoFiA - a novel simulation tool for central receiver systems, in: SolarPACES, Conference proceedings, Las Vegas, USA, 2013.

Griggs, D. J., Jones, D. W., Ouldridge, M., and Sparks, W. R.: Instruments and Observing Methods, Report No. 41, The First WMO Intercomparison of Visibility Measurements, Final Report, World Meteorological Organisation, 1989.

Gueymard, C.: Parameterized transmittance model for direct beam and circumsolar spectral irradiance, Sol. Energy, 71, 325-346, 2001.

Gueymard, C.: Direct solar transmittance and irradiance predictions with broadband models. Part 1: Detailed theoretical performance assessment, Sol. Energy 74, 355-379, 2003.

Gueymard, C.: Letter to the Editor: Visibility,aerosol conditions, and irradiance attenuation close to the ground - Comments on "Solar radiation attenuation in solar tower plants", edited by: Ballestrin J. and Marzo, A., Sol. Energy, 86, 1667-1668, 2012.

Hanrieder, N., Wehringer, F., Wilbert, S., Wolferstetter, F., PitzPaal, R., Campos, A., and Quaschning, V.: Determination of beam attenuation in tower plants, in: SolarPACES, Conference proceedings, Marrakech, Morocco, 2012. 
Hanrieder, N., Sengupta, M., Xie, Y., Wilbert, S. and Pitz-Paal, R.: Modelling Beam Attenuation in Solar Tower Plants Using Common DNI Measurements, ICEM 2015, Boulder, USA, to be submitted to Journal of Solar Energy, 2015.

Hess, M., Köpke, P., and Schult, I.: Optical properties of aerosols and clouds: the software package OPAC, Bull. Am. Soc., 79, 831-844, 1998.

Holben, B. N., Eck, T. F., Slutsker, I., Tanré, D., Buis, J. P., Setzer, A., Vermote, E., Reagan, J. A., Kaufman, Y. J., Nakajima, T., Lavenu, F., Jankowiak, I., and Smirnov, A.: AERONET - a federated instrument network and data archive for aerosol characterization, Remote Sens. Environ., 66, 1-16, 1998.

Kistler, B. L.: A User's Manual for DELSOL3: A Computer Code for Calculating the Optical Performance and Optical System Design for Solar Thermal Central Receiver Plants, Technical report, SANDIA, p. 78, 1986

Koschmieder, H.: Theorie der horizontalen Sichtweite, Beitraege zur Physik der freien Atmosphäre, 12, 33-53, 171-181, 1924.

Leary, P. L. and Hankins, J. D.: A user's guide for MIRVAL - A computer code for comparing design of heliostat-receiver optics for central receiver solar power plants, SAND77-8290, 1979.

Meyen, S., Lüpfert, E., Pernpeintner, J., and Fend, T.: Optical Characterization of Reflector Material for Concentrating Solar Power Technology, SolarPACES, Conference proceedings, 2009.

Mayer, B. and Kylling, A.: Technical note: The libRadtran software package for radiative transfer calculations - description and examples of use, Atmos. Chem. Phys., 5, 1855-1877, doi:10.5194/acp-5-1855-2005, 2005.

Mayer B., Kylling, A., Emde, C., Buras R., Hamann, U., Gasteiger, J., and Richter B.: libRadtran User's Guide, 2014.

OPTEC: Model LPV-3 and Model LPV-4, Long Path Visibility Transmissometer, Technical Manual for Theory of Operation and Operating Procedures, Technical report, 1-72, 2011.

Perez-Ramirez, D., Whiteman, D. N., Smirnov, A., Lyamani, H., Holben, B., Pinker, R., Andrade, M. and Alados-Arboledas, L.: Evaluation of AERONET precipitable water vapor versus microwave radiometry, GPS, and radiosondes at ARM sites, J. Geophys. Res. Atmos., 119, 9596-9613, 2014.

Pitman, C. L. and Vant-Hull, L. L.: Atmospheric transmission model for a solar beam propagating between a heliostat and a receiver, Conference proceedings, Proc. Annu. Meet., Am. Sect. Int. Sol. energy Soc., Volume 5, Houston, TX, USA, 1982

Ricchiazzi, P., Yang, S., Gautier, C., and Sowle, D.: SBDART: a research and teaching software tool for plane-parallel radiative transfer in the Earth's atmosphere, B. Am. Meteorol. Soc., 79, 2101-2114, 1998.
Schwarzbözl, P., Schmitz, M., and Pitz-Paal, R.: Visual HFLCAL a software tool for layout and optimization of heliostat fields, in: SolarPACES, Conference proceedings, Berlin, Germany, 2009.

Sengupta, M. and Wagner, M.: Atmospheric attenuation in central receiver systems from DNI measurements, in: SolarPACES, Conference proceedings, Marrakech, Morocco, 2012.

Shettle, E. P.: Models of aerosols, clouds, and precipitation for atmospheric propagation studies, in: Atmospheric Propagation in the UV, Visible, IR, and MM-Wave Region and Related Systems Aspects, AGARD Conference Proceedings, 454, 1-15, 1989.

Skupin, A., Ansmann, A., Engelmann, R., Baars, H., and Müller, T.: The Spectral Aerosol Extinction Monitoring System (SÆMS): setup, observational products, and comparisons, Atmos. Meas. Tech., 7, 701-712, doi:10.5194/amt-7-701-2014, 2014.

Smirnov, A., Holben, B. N., Eck, T. F., Dubovik, O., and Slutsker, I.: Cloud-screening and quality control algorithms for the AERONET database, Remote Sens. Environ., 73, 337-349, 2000 .

Stamnes, K., Tsay, S. C., Wiscombe, W., and Jayaweera, K.: Numerically stable algorithm for discrete-ordinate-method radiative transfer in multiple scattering and emitting layered media, Appl. Optics, 27, 2502-2509, 1988.

Stamnes, K., Tsay, S. C., Wiscombe, W., and Laszlo, I.: DISORT, a General-Purpose Fortran Program for Discrete-OrdinateMethod Radiative Transfer in Scattering and Emitting Layered Media: Documentation of Methodology, Version 1.1, March 2000.

Tahboub, Z. M., Abaidli, A. A. A., Luque, F., Salbidegoitia, I., Farges, O., Hassar, Z., Oumbe, A., Geuder, N., and Goebel, O.: Solar beam attenuation experiments - Abu Dhabi, SolarPACES, Conference proceedings, Marrakech, Morocco, 2012.

Torresol: available at: http://www.torresolenergy.com, last access: 15 January 2014.

Vaisala: User's Guide: Present Weather Sensor FS11P, 2010.

Vittitoe, C. N. and Biggs, F.: terrestrial propagation loss, in: Amer. Sec. ISES Meeting, Denver, August 1978, Sandia Release, 1978

Washington, R., Todd, M., Middleton, N. J., and Goudie, A. S.: Dust-storm source areas determined by the Total Ozone Monitoring Spectrometer and surface observations, Ann. Assoc. Am. Geogr., 93, 297-313, 2003. 